\title{
Intelectuais gaúchos e o Estado Novo brasileiro (1937-1945)
}

\author{
The gaucho intellectuality and the Brazilian Estado Novo (1937-1945) \\ Intelectuales gauchos y el Estado Novo brasileño (1937-1945)
}

RenéE.Gertz

\section{Resumo}

As relações entre intelectuais brasileiros e o Estado Novo (1937-1945) estão relativamente bem estudadas. Em geral, porém, estudos sobre essa temática não incluem a situação do Rio Grande do Sul. Aqui se faz uma tentativa de caracterizar a relação dos intelectuais gaúchos com o regime implantado em novembro de 1937.

Palavras-chave: Estado Novo. Intelectuais. Rio Grande do Sul.
O assim chamado primeiro governo de Getúlio Vargas (1930-1945) como um todo, e, dentro dele, em especial a fase expressamente ditatorial iniciada em 1937, com a implantação do assim chamado Estado Novo, constitui momento privilegiado no qual ocorreu uma discussão profunda sobre nação, nacionalidade e nacionalismo, no Brasil, envolvendo agentes de Estado e intelectuais. ${ }^{1}$

Tentativas de aproximação do aparelho de Estado a intelectuais, na preocupação de obter sua colaboração para a definição dos rumos da nação, são registradas desde o início do Brasil independente. “Uma vez

\footnotetext{
Professor no Departamento de História da Pontifícia Universidade Católica do Rio Grande do Sul; professor aposentado pela Universidade Federal do Rio Grande do Sul.
} 
implantado o Estado Nacional, impunha-se como tarefa o delineamento de um perfil para a 'Nação brasileira', capaz de lhe garantir uma identidade própria no conjunto mais amplo das 'Nações', de acordo com os novos princípios organizadores da vida social do século XIX". ${ }^{2}$ Para isso, foi criado o Instituto Histórico e Geográfico, que contaria com cinquenta acadêmicos, isto é, intelectuais, que deveriam indicar a direção em que caberia à "nacionalidade" desenvolver-se. E

já por ocasião da sua reunião de constituição, a $1^{\circ}$ de dezembro de 1838 , o Instituto Histórico colocava-se sob a proteção do imperador, proteção esta que terá como expressão uma ajuda financeira, que a cada ano significará uma parcela maior do orçamento da instituição. Cinco anos após a sua fundação, as verbas do Estado Imperial já representavam $75 \%$ do orçamento do IHGB, porcentagem que tendeu a se manter constante ao longo do século XIX. Tendo em vista que, para a realização de seus projetos especiais, tais como viagens exploratórias, pesquisas e coletas de material em arquivos estrangeiros, o IHGB se via obrigado a recorrer ao Estado com o pedido de verbas extras, pode-se avaliar como decisiva a ajuda do Estado para sua existência material. ${ }^{3}$

O recurso a intelectuais para imaginar e definir a nacionalidade brasileira perpassou o restante da monarquia, estendendo-se pela República. Éder Silveira tentou demonstrar uma linha de continuidade entre escolas aparentemente tão diferentes quanto o romantismo do século XIX (império) e o modernismo no século XX (república), numa comparação das preocupações de um José de Alencar e de um Oswald de Andrade com a nacionalidade brasileira.
Ao contrário de certo senso comum, o modernismobrasileiro não rompe com o século XIX. A linguagem de ruptura e de terra arrasada faz parte da linguagem de manifesto, mas na prática penso ter sido capaz de mostrar que os modernistas em geral, e Oswald de Andrade em particular, resignificam preocupações que são próprias aos românticos, como nação e nacionalidade, conceitos que se definem pelos mesmos elementos, que são a língua nacional, a história e os mitos de origem. ${ }^{4}$

A escrita da História no Brasil está muito pautada pelas pesquisas desenvolvidas no centro do país, nominadamente em São Paulo e no Rio de Janeiro. Isso significa que também os estudos que abordam as relações entre os integrantes do aparelho de Estado e os intelectuais baseiam-se, sobretudo, na realidade vivenciada nesses dois estados. Acontece que, no mínimo desde a implantação da república, encara-se o Rio Grande do Sul como uma das unidades da federação que teria trilhado um caminho político peculiar, diferenciado do restante do país. ${ }^{5}$ Esse caminho peculiar estava ideologicamente acompanhado pela doutrina positivista, de forma que se justifica a pressuposição de que grande parte dos intelectuais gaúchos estivesse alinhada a essa corrente, uma distinção possível em relação àqueles dos demais estados. Numa perspectiva a posteriori, por sua vez, é interessante constatar que um número significativo de intelectuais sul-rio-grandenses manifestou, ao final do Estado Novo, justamente indignação diante daquilo que eles consideravam excesso de centralismo nacionalizador praticado durante o período anterior. Essa manifestação resultou, inclusive, na fundação de uma revista que tinha como papel funda- 
mental denunciar esses excessos, e recuperar as peculiaridades e diferenças da parte (o Rio Grande do Sul) frente ao todo (o Brasil).

Quando, em 1945, o Estado Novo estava em decadência, intelectuais gaúchos criaram a revista Província de São Pedro. ${ }^{6}$ A direção ficou a cargo de Moysés Vellinho, o qual, na apresentação ao primeiro número, escreveu que, apesar de todos os esforços, a nacionalidade brasileira ainda não estava definida, motivo pelo qual não "se poderá admitir, já agora, que o sentimento de unidade de uma pátria de fronteiras quase ilimitadas se possa consolidar mediante a anulação das diversidades regionais". Por isso, propôs um "provincianismo cultural", "como o mais lúcido dos programas, se queremos chegar à ampla compreensão dos brasileiros entre si, para a definitiva assimilação de uma terra de dimensões imperiais, e que, em grande parte, ainda se pertence mais a si mesma que ao homem". Mais adiante, o editorialista afirmou: "Guardando-se dos perigos de um tradicionalismo estreito e das pieguices do saudosismo, [a revista] terá sempre presente, no entanto, os elementos fundamentais da tradição local, os autênticos valores do passado, porque acredita que a preservação de certas fixações é indispensável à caracterização de uma cultura".

Se até este ponto tentava explicar a causa pela qual a revista se bateria, identificou, a seguir, os inimigos que enfrentaria:

Se de tudo resultar uma nova afirmação das nossas peculiaridades regionais, é bem possível que os maníacos da centralização se encham de suspeitas e temores. Não faz mal. Parece fora de dúvida que os assomos de padronização cultural só podem concorrer para a consumação da mais ingrata das obras: a descaracterização do país na sua unidade múltipla como consequência do gradual apagamento das fisionomias locais e da destruição dos valores da província (p. 6-7).

Aqui transparece, de maneira clara, uma crítica à política centralizadora e uniformizadora, enfim, nacionalizadora, praticada durante o período imediatamente anterior. Justifica-se, por isso, uma tentativa de caracterizar o posicionamento de intelectuais gaúchos frente ao governo, frente ao poder político do Estado Novo e, também, como os detentores desse governo, desse poder eventualmente lidaram com os intelectuais regionais. ${ }^{7}$ Os dados obtidos ainda não são muitos, mas tudo indica para uma direção relativamente inequívoca. É isso que se tentará mostrar no restante deste texto, à mão de alguns exemplos representativos.

Comecemos pelo próprio Moysés Vellinho. Militante do Partido Republicano Rio-grandense, antes de 1930, assumiu cargos de alguma relevância na administração federal logo após a revolução daquele ano, voltou ao Rio Grande do Sul para ser deputado estadual pelo agora "oficial" Partido Liberal Rio-grandense, de 1935 a 1937. Entre 1939 e 1945, exerceu o importante cargo de conselheiro do Departamento/Conselho Administrativo de Estado, um órgão muito importante da administração estadual, pois tinha a função de assessorar e, em algum sentido, fiscalizar o Poder Executivo. ${ }^{8}$

Em situação semelhante à de Vellinho - mesmo que, eventualmente, não exercendo cargos tão elevados quanto ele -, encontravam-se vários outros intelectuais. Um deles foi Manoelito de Ornellas, que naquele 
momento já havia produzido vários livros de ficção e de ensaio, que foi diretor da Biblioteca Pública, diretor da Imprensa Oficial, e como tal editor do Jornal do Estado, porta-voz do governo. A partir de 1943, foi chefe do o Departamento Estadual de Imprensa e Propaganda (DEIP), ainda que a ocupação desse cargo se tenha dado após a saída do interventor Cordeiro de Farias, quando ocorreu uma tentativa de descompressão da política estadual, de forma que, possivelmente, tenha justificado sua atitude como esforço para colaborar nessa "liberalização" do regime. Não há dúvida de que sua biografia apresenta alguns atos que apontam nessa direção. ${ }^{9}$

Histórias semelhantes poderiam ser contadas a respeito de Aurélio Porto, Alcides Maia, Athos Damasceno Ferreira, Augusto Meyer, Limeira Tejo, Carlos Dante de Moraes, Carlos Reverbel, Darcy Azambuja, Ernesto Pellanda, Fortunato Pimentel, Mário Quintana, Walter Spalding, nomes mais conhecidos na formação da opinião pública regional, que, em maior ou menor grau, vinham de uma militância político-intelectual da Primeira República gaúcha e conviveram sem maiores dificuldades com o Estado Novo.

Ao lado desses intelectuais de feitio mais "tradicional" - que, do ponto de vista político, podiam ser republicanos, libertadores ou mesmo apolíticos -, havia três outros grupos. Um deles era constituído por aqueles que haviam flertado com ou aderido ao fascismo, seja o internacional, seja o brasileiro representado pela Ação Integralista Brasileira (AIB). Em especial após a "intentona integralista" de maio de 1938 e, mais ainda, com a entrada do Brasil na Segunda Guerra Mundial, vários deles enfrentaram dificuldades. Félix Contreiras Rodrigues, por exemplo, esteve exilado, e foi acusado de conspirar com o deposto governador Flores da Cunha, a partir do Uruguai. ${ }^{10}$ Também Dario de Bittencourt, um dos integrantes da trindade que havia fundado a AIB, no estado, mesmo tendo feito carreira universitária como professor na Faculdade de Direito da Universidade de Porto Alegre, então subordinada ao governo estadual, foi convocado à polícia, em várias oportunidades, além de ter sido constrangido com denúncias de ter mantido relações estreitas com o nazismo. ${ }^{11}$

Situação diferente foi vivenciada por Anor Butler Maciel, outra figura proeminente da AIB, conhecido por seu antissemitismo, expresso num livro de 1937 sob o título Nacionalismo - o problema judaico e o nacional-socialismo. ${ }^{12}$ Saudou, de alguma forma, a implantação do Estado Novo, dedicando um livro à análise de sua estrutura. ${ }^{13}$ Talvez por essa manobra, não só foi tolerado, mas premiado com um importante cargo na estrutura de Estado, tendo sido procurador-geral estadual de agosto de 1939 a maio de 1941. Consta que mesmo nesse cargo teria tomado ao menos uma medida de caráter antissemita, quando demitiu a procuradora judia Sophia Galanternick Sturm. ${ }^{14}$

Outro grupo era aquele integrado por intelectuais que assumiam uma posição de crítica social e política que se poderia classificar de esquerda. Cabe citar três deles: Cyro Martins, Lila Ripoll e Dyonélio Machado. O primeiro publicou, durante o período, livros de clara crítica social - como Enquanto as águas correm (1939), Mensagem errante (1942), Por- 
teira fechada (1944) -, mas não há registro de maiores constrangimentos sofridos, de parte de autoridades. Em entrevista posterior, admitiu que, numa comparação com Dyonélio Machado, sempre fora bem mais moderado. Nessa mesma entrevista, há uma indicação de que - como se verá mais adiante, para o caso de Érico Veríssimo - até tenha encarado o regime estado-novista em certo sentido progressista. A frase é a seguinte (referindo-se à Porteira fechada): "Aparece também aí a decadência dos coronéis, porque o Estado Novo, ao liquidar com os partidos políticos, automaticamente anulou a força dos mandachuvas tradicionais da República Velha" ${ }^{15}$

A segunda intelectual, apontada como ligada ao Partido Comunista desde no mínimo 1935, aparentemente, também não sofreu restrições significativas, pois exercia um cargo de confiança na Secretaria de Educação. Consta como participante de ações patrióticas, pois seu nome aparece nas listas de julgadores de frases alusivas a comemorações cívicas.

Mas, sem dúvida, o nome mais relevante e emblemático desse grupo é o terceiro. Como se sabe, Dyonélio Machado exercera cargo importante na organização da esquerdista, antifascista Aliança Nacional Libertadora, tendo sido seu presidente estadual. ${ }^{16}$ Após o fechamento da ANL, em julho de 1935, fora preso por distribuir panfletos que criticavam esse fechamento. Condenado, cumpriu pena em condições muito duras, no Rio de Janeiro, entre agosto de 1936 e junho de 1937. Temendo novas represálias, fugiu para o interior de Santa Catarina quando foi decretado o Estado Novo, em 10 de novembro desse último ano.
No seu caso, porém, aconteceu algo parecido com aquilo que se deu em nível federal com alguns intelectuais considerados de esquerda - como Carlos Drummond de Andrade, que exerceu importante função no Ministério da Educação. Se não houve uma tentativa de cooptação expressa em relação a Dyonélio Machado por parte das autoridades, há, ao menos, sinais de que foram tomadas algumas medidas para reverter a impressão de que ele fosse considerado inimigo a ser perseguido. $\mathrm{O}$ interventor federal que administrou o estado de 1938 a 1943, Oswaldo Cordeiro de Farias, muito logo assinou um ato anistiando-o e reintegrando-o em sua função de médico-chefe de divisão do Hospital Psiquiátrico São Pedro. ${ }^{17}$

Por outro lado, há indícios de que ele próprio correspondeu aos acenos e às iniciativas de integrantes do aparelho de Estado para aparentar tolerância e até benevolência em relação à intelectualidade. Um dos episódios que apontam nessa direção ocorreu por ocasião dos muito divulgados festejos do suposto bicentenário de Porto Alegre, promovidos pelo interventor no município, José Loureiro da Silva. Entre os vários eventos patrocinados pelo poder público como um congresso de História e Geografia -, recebeu destaque especial um almoço festivo específico para os intelectuais. A ele compareceram, inclusive, interventores (governadores) de outros estados brasileiros e intelectuais gaúchos que, naquele momento, viviam fora do Rio Grande do Sul, como, por exemplo, Vianna Moog. Na listagem de mais de cem nomes qualificados como de intelectuais gaúchos presentes ao ato, publicada pela imprensa, consta também Dyonélio Machado. ${ }^{18}$ 
Tudo isso não significa que o escritor não tivesse sido incomodado de forma alguma, durante o período. Como o próprio Dyonélio relatou em suas Memórias de um pobre homem, em outubro de 1942 publicou na Revista do Globo um conto intitulado "Noite no acampamento", que motivou uma convocação à polícia, para dar explicações..$^{19}$ É possível que esse constrangimento policial tenha sido provocado por pressão do exército, já que o tema do conto foi a Guerra do Paraguai, e um tenente-coronel chamado Correia Lima o criticou publicamente, no Diário de Notícias de 17 de novembro do citado ano.

Ainda que se devesse fazer uma investigação profunda para uma conclusão mais consistente, há indícios de que alguns colegas intelectuais mantinham maior distanciamento em relação a ele que certas autoridades. Em 11 de novembro de 1938, por exemplo, lhe foi prestada uma homenagem, que teria sido organizada por Érico Verissimo, à qual, no entanto - a crer nas referências nominais publicadas pela imprensa - compareceram poucos intelectuais..$^{20}$ Gláucia Konrad também registrou que O louco do Cati, de 1942, teria sido resenhado com simpatia reduzida, por alguns colegas. ${ }^{21}$

Finalmente, o terceiro grupo de intelectuais que merece referência é o dos católicos. Como em todo o Brasil, setores ligados à Igreja Católica trabalhavam, desde a década de 1920, no restabelecimento da força dessa instituição dentro do Estado e da sociedade brasileiros. No Rio Grande do Sul, essa luta pela ampliação da presença católica era capitaneada, politicamente, pelo arcebispo de Porto Alegre, D. João Becker, intelectualmente, pelo padre jesuíta Werner von und zur Mühlen, do qual era discípulo Armando Câmara, cujos trabalhos e atividades ganharam notoriedade na década de $1930 .{ }^{22}$ Do grupo de intelectuais claramente identificados com essa causa, podem ser citados, além de muitos outros, Adroaldo Mesquita da Costa, Aldo Obino, Álvaro Magalhães, Armando Câmara, Dámaso Rocha, Fábio de Barros, Luiz Gonzaga Jaeger (jesuíta) e Ruy Cirne Lima. Esse grupo deu apoio sólido ao status quo político instaurado em 1937. Em várias oportunidades, propôs antes "ultrapassar" o regime pela direita, do que fazer-lhe oposição, isto é, em algumas situações criticou as autoridades por suposta conivência com excessos de liberdade.

Para encerrar, será apresentado um exemplo paradigmático e sintetizador da situação, das posições e dos dilemas de grande parte dos intelectuais gaúchos diante do Estado Novo. Trata-se de Érico Veríssimo, então em plena ascensão no firmamento intelecto-cultural do estado. O dono da Editora do Globo, a quem Veríssimo e muitos outros aqui referidos estavam ligados, afirmou, muitos anos depois, que "naquela época só havia dois títulos importantes: ou se era comunista ou fascista. O desprezível terceiro era alguém que se rotulava democrata". ${ }^{23}$ Ainda que tenha havido intelectuais que se esforçaram em continuar defendendo a liberal-democracia, a polarização entre os defensores/detratores dos dois sistemas citados estava sempre presente, e a desafiar os formadores de opinião.

No segundo semestre de 1935, a conjugação de acontecimentos nacionais e internacionais levou a um acirramento do embate entre as duas visões de mundo. In- 
ternamente, a esquerdista Aliança Nacional Libertadora fora fechada pelo governo federal, em julho, com a subsequente onda de perseguições, que, inclusive, levaram ao processo e à posterior condenação de Dyonélio Machado. ${ }^{24}$ Em nível internacional, a Itália fascista invadiu a Abissínia, desencadeando uma reação muito forte por parte da esquerda e de democratas do mundo ocidental, incluindo parte dos intelectuais gaúchos. ${ }^{25}$ Nesse contexto, aconteceu uma importante manifestação capitaneada por Érico Veríssimo. No dia 15 de outubro, o Correio do Povo publicou um "a pedido" intitulado "Aos intelectuais do Rio Grande do Sul" (p. 9), manifesto que iniciava com a seguinte afirmação:

A hora trágica que vive a humanidade, presa das ambições que a lançam em novas carnificinas, vítima de ditaduras disfarçadas ou declaradamente fascistas, e por elas entravada na evolução natural que se vinha processando em prol dos princípios de "Justiça" e "Liberdade" exige dos intelectuais de todo mundo uma atitude desassombrada de defesa das conquistas da civilização e da cultura.

De forma concreta, o texto apontou para aquilo que estava acontecendo na Itália - ainda que não haja referência nominal à invasão da Abissínia, que fora ordenada por Mussolini em 3 de outubro ${ }^{26}$-, mas destacava, sobretudo, a investida contra a cultura acontecida na Alemanha nazista através da queima pública de livros, tornada tanto mais abominável pelo fato de ter tido a participação de estudantes universitários.

O manifesto, porém, não se restringiu à cena internacional. "No Rio Grande, como em todo o Brasil, esse protesto [dos intelec- tuais] se torna indispensável pela crescente ameaça de aniquilamento da democracia, por leis compressoras e atentatórias da liberdade de pensamento, dos direitos de reunião e associação, e das mais rudimentares garantias individuais e sociais", enquanto haveria tolerância em relação a "idiotas de mal disfarçado fascismo". ${ }^{27}$ Por tudo isso, os intelectuais gaúchos foram conclamados a participar da fundação de um Centro de Cultura, no qual essa situação pudesse ser discutida e enfrentada.

A lista dos signatários foi encabeçada por Érico e denota certa coragem de sua parte, pois, dos 34 nomes nela constantes, aqueles de intelectuais e artistas mais conhecidos são relativamente poucos. Cabe citá-los: Arlindo Pasqualini, Carlos Macedo Reverbel, Fernando Corona, Lila Ripoll, Maurício Rosenblatt, Mem de Sá, Nelson Boeira Faedrich, Nilo Ruschel e Rivadávia de Souza. ${ }^{28}$ Isso significa que, naquele momento, a crítica tanto ao fascismo quanto ao status quo nacional e regional não contava com o entusiasmo de muitos intelectuais gaúchos. Segundo Veríssimo, em suas memórias, o romance Caminhos cruzados, do mesmo ano de 1935, havia gerado muitos desafetos à sua pessoa, ao ponto de ter sido convocado ao Departamento de Ordem Política e Social, onde teria sido fichado como comunista. "Para essa classificação, muito contribuiu o fato de ter eu, naquele ano de 1935, encabeçado as assinaturas de um manifesto antifascista em que visávamos não só o fascismo nacional, como também o alemão e o italiano" ${ }^{29}$

Três meses depois desse manifesto foi publicado outro, desta vez por simpatizantes do fascismo italiano. Em 21 de janeiro 
de 1936, o Correio do Povo publicou um texto maior que o anterior, sob o título "Pela causa da Itália" (p. 7). Começava com a seguinte frase:

No ingrato momento em que o imperialismo plutocrático, esquecido da sua velha, implacável capacidade de agressão, teima em reclamar para si, em nome de princípios que sempre atropelou, o tenebroso direito de sonegar à Itália até mesmo a faculdade primária de respirar, nós, intelectuais do Rio Grande do Sul, vimos protestar nossa inteira solidariedade moral à egrégia pátria mediterrânea.

A solidariedade para com a Itália foi justificada com o fato de os signatários se sentirem "tributários do espírito latino". Ao contrário das guerras de conquista, a ação "na África Oriental tem, sobretudo, um sentido biológico". "Não precisa esconder-se quem apenas procura oxigênio para seus pulmões". "E quem tem mais direito à vida que a luminosa península adriática, pelas suas origens e tradições, pelo seu espírito, sua vitalidade e sua cultura, pela sua experiência, pela sua dignidade e pelo seu sangue?". "A gloriosa península não se lançou nessa guerra pelo prazer obscuro de conquistar. Dentro dos princípios darwinianos, o seu gesto de sangue é menos um ímpeto de agressão que um movimento de defesa". "É pena que os manipuladores da Liga das Nações, tão ciosos da integridade geográfica desse vasto país bárbaro, e de bárbaros, que é a Etiópia, que vivem à custa dos povos que subjugaram, invertam tendenciosamente os termos da questão ítalo-abissínia e coloquem no mesmo pé de igualdade a luminosa pátria de Dante e os sombrios domínios do longínquo e desajeitado herdeiro de
Salomão". "A Abissínia é uma ficção política". "A luta, em última análise, não é entre a Itália e a Abissínia", mas sim entre a Itália e obscuros interesses de grandes potências.

No final do texto com esse teor, constavam os seguintes nomes como signatários: Athos Damasceno Ferreira, Armando Silveira, Alceu Barbedo, Constantino Martins, Dámaso Rocha, De Souza Júnior, Dante de Laytano, Érico Veríssimo, Eduardo Duarte, Emílio Kemp, Félix Contreiras Rodrigues, Fábio de Barros, João C. de Freitas, J. P. Coelho de Souza, Moysés Vellinho, Mário Quintana, Manoelito de Ornellas, Ovídio Chaves, Oscar Dauth Filho, Paulo de Gouvêa, Reinaldo Moura, Telmo Vergara.

Como se vê, se o manifesto anterior continha 34 assinaturas, este arrolava apenas 22, mas aqui aparecem mais "estrelas" que no anterior. Tendo em vista o caráter público do manifesto coordenado por Érico Veríssimo, de 15 de outubro do ano anterior, não está claro se seu nome constou por algum engano dos organizadores deste último ou por um ato consciente de provocação, pois não é possível imaginar que alguém pudesse esperar que ele o endossasse. No dia 22 de janeiro de 1936, o Correio do Povo, em sua obscura página 4 , publicou uma declaração que dizia o seguinte:

Vimos com surpresa o nosso nome entre os intelectuais que assinaram o manifesto "Pela causa da Itália" recentemente publicado. Temos a declarar a respeito: a) que desconhecíamos em absoluto os seus termos; b) que estamos em completo desacordo com seu texto; c) que não assinamos nem demos a ninguém autorização para isso. Queiram ter a fineza de publicar esta declaração. Muito gratos, firmamos, Érico Veríssimo, Telmo Vergara, Mário Quintana. 
Ao contrário do pressuposto ainda assumido por um polemista em 1994, os fatos ocorridos em 1935/1936 efetivamente não depõem contra, mas sim a favor de Érico Veríssimo. ${ }^{30}$ Mas a vida continuou, e aí veio a decretação do Estado Novo, em 10 de novembro de 1937 e nesse novo contexto o Jornal do Estado, órgão oficial do governo gaúcho, publicou, em sua edição de 18 de abril de 1938 (p. 3), uma informação sobre a formação de um Comitê de Propaganda do Estado Novo, por iniciativa de Viriato Vargas, irmão de Getúlio. Na reunião em que foi decidida a criação desse comitê, estiveram presentes intelectuais como Moysés Vellinho, Dante de Laytano, Telmo Vergara, Oliveira [Limeira?] Tejo, e Érico Veríssimo. A presença deste não deve ter sido secundária, pois na reunião foi decidido que seria apresentada uma série de palestras radiofônicas com o objetivo de desencadear uma mobilização a favor do regime, e a primeira palestra seria apresentada por ele. Assim, o mesmo jornal, uma semana depois, em 25 de abril de 1938 (p. 4), transcreveu a fala do escritor, pela Rádio Farroupilha.

A fala começou didático-infantil: "Era uma vez o coronel Chicuta, chefe político do município de Jacarecanga, onde era prefeito o não menos prestigioso coronel Tinoco. Um belo dia o coronel Tinoco briga com o coronel Chicuta por causa do maldito bueiro da rua Voluntários da Pátria. Agita-se o povo de Jacarecanga. Cisão no partido. Descomposturas escritas e orais. Telegramas para o governo do Estado". Verissimo continuou explicando que o caso se espalhava para o nível estadual, depois para o federal, desencadeando uma crise revolucionária, com que o país sofreria enormes prejuízos. "Esta era, meus amigos, em traços de caricatura, a situação brasileira anterior ao Estado Novo". Os excessos de descentralização levavam a esse tipo de aberração.

“E a todas essas - onde ficava o Brasil como unidade, como nacionalidade, como todo, como pátria comum?". "E nessa cegueira caminhávamos para a catástrofe. E é desse desastre que o Estado Novo nos procura salvar". Ele poderia evitar que aqui viesse a ocorrer aquilo que acontecera na Espanha. Depois, o palestrante passou a referir-se à cobiça internacional que estaria de olho no país, louvando, por consequência, a nacionalização do ensino, desencadeada pelo secretário de educação J. P. Coelho de Souza: ${ }^{31}$ "Sempre defendi a aproximação pan-americana. Hoje o Brasil está integrado nessa política". Ele, pessoalmente, sempre teria combatido o racismo e defendido a adoção de leis trabalhistas - coisas que o regime estaria realizando. "Reduzindo a situação do Brasil a uma imagem bem simples, poderíamos compará-lo a uma menina bonita e dona de vastas e riquíssimas terras que está sendo cobiçada por velhos, hábeis e maliciosos caçadores de dotes".

Permitam-me ainda uma confissão. No dia 10 de novembro de 1937, recebi a proclamação do Estado Novo com sérias desconfianças e num grande abatimento. Os horizontes estavam ainda escuros. Tive a impressão de que era a ditadura integralista que seria anunciada. Pensei assim: não se pode mais escrever no Brasil. E mais tarde: é até possível que não se possa mais viver nesta terra. Virão as perseguições e a violência, a intolerância e o ódio. Quanto custará uma passagem para a Cochinchina? Mas os fatos, meus amigos - tomem 
nota -, os fatos se encarregaram de provar que felizmente eu me enganava. Nem esquerda nem direita, mas sim o centro, que é o equilíbrio e o bom senso. Nenhum homem de boa vontade pode negar o seu apoio ao Estado Novo.

Em resumo, a fala reproduziu as razões que levaram Verissimo a manifestar, de público, seu apoio ao regime implantado em novembro de 1937: o combate aos efeitos dissolventes do coronelismo e a consequente possibilidade de construção da nacionalidade, as ameaças externas, ${ }^{32}$ o controle dos extremismos de direita e de esquerda.

Documentação inédita do arquivo de Érico Veríssimo talvez pudesse nuançar seu posicionamento em relação ao regime estado-novista, no decorrer dos anos seguintes. Mas há indícios de que não entrou em rota de colisão clara com os detentores do poder. Em julho de 1938, foi prestada uma homenagem a ele pela publicação de Olhai os lírios do campo, ocasião em que esteve presente Ibanez Verney, secretário do interventor federal. Em junho de 1939, seu nome esteve entre aqueles que prestigiaram uma homenagem ao jornalista André Carrazoni, que acabara de publicar uma biografia de Getúlio Vargas. Em 1940, participou da citada grande festa oferecida pelo prefeito-interventor Loureiro da Silva. Após voltar de sua primeira viagem aos Estados Unidos, em 1941, fez uma visita de cortesia ao interventor federal que governava o estado, para relatar suas impressões sobre aquele país. Em junho de 1943, o ex-tenente João Alberto Lins e Barros, agora coordenador nacional de mobilização econômica do governo federal, em uma visita a Porto Alegre, foi recebido pelo escritor. ${ }^{33}$ Isso indica que as auto- ridades não o relegaram ao ostracismo nem ele se mostrou arredio a elas.

Existe, obviamente, o rumoroso caso de seu confronto com o padre Fritzen, em 1943, o qual, muitas vezes, foi apresentado como um brado de oposição contra a ditadura estado-novista. ${ }^{34}$ Mas, provavelmente, se tratava muito mais de uma tentativa de obstacularizar o avanço do grupo dos católicos, os quais, como foi referido, muitas vezes, tentavam ultrapassar o regime pela direita, cobrando ações mais enérgicas no campo cultural, e mesmo político, contra grupos ou tendências que consideravam deletérios.

Para concluir: mais ou menos como aconteceu no Brasil todo, também no Rio Grande do Sul a massa da intelectualidade não fez oposição cerrada ao regime ditatorial implantado em 1937, nem os detentores do poder regional promoveram uma repressão ou mesmo apenas uma pressão generalizada contra ela. Como mesmo regimes ditatoriais não são monolíticos, é óbvio que houve casos de perseguição à inteligência gaúcha, mas a orientação básica era a de tentar conviver sem grandes atritos e, se possível, cooptá-la. A moeda de troca eram as promessas ou algumas medidas efetivas para consolidar a nacionalidade, com políticas nessa direção nos campos econômico, social, educacional e cultural, para construir um país unitário e moderno. Para alguns intelectuais, as benesses pessoais derivadas de certo mecenato estatal não terão sido desprezadas para aceitar uma convivência minimamente harmônica com a ditadura. Há que se destacar, sobre isso, que mesmo que, talvez, muitos deles não fossem estatólatras, certamente contribuíram para a consolida- 
ção de uma ideologia ou mentalidade que destaca os benefícios de um máximo possível de Estado. Afinal, o Rio Grande do Sul, até hoje, é visto como o lugar de origem de uma visão de mundo que apresenta e louva o Estado como demiurgo capaz de nos presentear com um paraíso terrestre. E esse posicionamento convive muito bem com a admissão de arranhões ao Estado Democrático de Direito, muitas vezes sob a justificativa de garantir os interesses da "nação" ${ }^{35}$

\section{Abstract}

The relations between the Brazilian intellectuality and the Estado Novo (19371945) are relatively well researched. But the studies usually don't include the situation in the southern state of Rio Grande do Sul. This article is an attempt to characterize the relations of the gaucho intellectuality with the political regime proclaimed in November 1937.

Keywords: Estado Novo. Intellectuality. Rio Grande do Sul.

\section{Resumen}

Las relaciones entre intelectuales brasileños y el Estado Novo (1937-1945) están relativamente bien estudiadas. En general, sino, estudios sobre este tema no incluyen la situación del Rio Grande do Sul. Aquí se hace una breve tentativa de caracterizar la relación de los intelectuales gauchos con el régimen implantado en noviembre de 1937.

Palabras clave: Estado Novo. Intelectuales. Rio Grande do Sul.

\section{Notas}

1 A referência clássica é MICELI, Sérgio. Intelectuais e classe dirigente (1920-1945). São Paulo: DIFEL, 1979. Mas há outras referências importantes: VELLOSO, Mônica Pimenta. Os intelectuais e a política cultural do Estado Novo. Rio de Janeiro: FGV/ CPDOC, 1987; PÉCAUT, Daniel. Os intelectuais e a política no Brasil: entre o povo e a nação. São Paulo: Ática, 1990, p. 19-96; ROLLAND, Denis. O estatuto da cultura no Estado Novo: entre o controle das culturas nacionais e a instrumentalização das culturas estrangeiras. In: BASTOS, Elide Rugai; RIDENTI, Marcelo; e ROLLAND, Denis (Org.). Intelectuais: sociedade e política. São Paulo: Cortez, 2003, p. 85-111.

2 GUIMARÃES, Manoel Luis Salgado. Nação e civilização nos trópicos: o Instituto Histórico e Geográfico Brasileiro e o projeto de uma história nacional. Estudos Históricos, Rio de Janeiro: FGV, n. 1, p. 6, 1988.

3 Ibid., p. 9.

4 SILVEIRA, Éder. Tupi or not tupi: nação e nacionalidade em José de Alencar e Oswald de Andrade. Porto Alegre: EDIPUCRS, 2009, p. 248.

5 GERTZ, René E. O Sonderweg do Rio Grande do Sul. Estudos Ibero-Americanos, Porto Alegre: PUCRS, v. 37, n. 2, p. 215-321, 2011.

6 GERTZ, René E. Intelectuais gaúchos pensam o Rio Grande do Sul. Estudos Ibero-Americanos, Porto Alegre: PUCRS, v. X, n. 1, p. 79-113, 1984.

7 Isso não significa desconhecer a tese de que o Estado Novo brasileiro deve, justamente, ser explicado como produto da tradição gestada pelo positivismo castilhista-borgista, no Rio Grande do Sul, da qual Getúlio Vargas provinha. Cf., a respeito, HENTSCHKE, Jens R. Positivism gaúcho-style: Júlio de Castilho's dictatorship and its impact on state and nation-building in Varga's Brazil. Berlim: Verlag für Wissenschaft und Forschung $\mathrm{GmbH}$, 2004. "My thesis is that the polity and policies of the authoritarian-corporatist Estado Novo can, to large extent, already be identified in Rio Grande do Sul before the Great Depression. The southern state's positivist developmental and educational dictatorship, established by Júlio de Castilhos, had represented an alternative political model in Brazil's Old Republic... When Getúlio Vargas and his fellow gaúchos took over central government in 1930 and rebuilt state and nation to an extent never seen before, Rio Grande's positivist project remained their guiding example" (p. 5). 
8 GERTZ, René E. O Estado Novo no Rio Grande do Sul. Passo Fundo: Editora da UPF, 2005, p. 64-65.

9 Em uma entrevista ao Correio do Povo, em 26 de janeiro de 1944 (p. 3), não falou de benefícios liberalizantes que uma seção estadual do DIP (o DEIP) traria ao estado, mas destacou vantagens, como a inclusão da divulgação de aspectos positivos sobre o estado no restante do país, e até de benefícios materiais para os intelectuais. As possibilidades liberalizantes estiveram subentendidas, com a troca do interventor federal Oswaldo Cordeiro de Farias por Ernesto Dornelles: “A cultura e a seriedade do coronel Ernesto Dornelles, conhecidos e proclamados em todos os meios que frequentamos na Capital Federal, cercam de prestígio o governo do Rio Grande do Sul". Aqui ao menos transparece a ideia de que a criação do DEIP - e sua nomeação para chefiá-lo - fazia parte de um projeto liberalizante, fato que, naturalmente, justificaria seu envolvimento no caso.

10 BELLINTANI, Adriana Iop. Conspiração contra o Estado Novo. Porto Alegre: EDIPUCRS, 2002, p. 75.

11 BITTENCOURT, Dario de. Curriculum vitae - documentário - (1910-1957). Porto Alegre: Ética Impressora Ltda., 1958, passim. A respeito de sua condição de intelectual negro, cf. SANTOS, José Antônio dos. Prisioneiros da História: trajetórias de intelectuais na imprensa negra meridional. Porto Alegre: PUCRS, 2011. Tese (Doutorado em História), p. $210-240$.

12 MACIEL, Anor Butler. Nacionalismo - o problema judaico e o nacional-socialismo. Porto Alegre: Globo, 1937. Para uma análise dessa obra, cf. VIEIRA, Newton Colombo de Deus. Além de Gustavo Barroso: o antissemitismo na Ação Integralista Brasileira (1932-1937). Porto Alegre: PUCRS, 2012. Dissertação (Mestrado em História), p. 92-97.

13 MACIEL, Anor Butler. Subsídios para o estudo da estrutura política do Estado Novo. Porto Alegre: Globo, 1937.

14 FÉLIX, Loiva Otero. Histórias de vida do Ministério Público do Rio Grande do Sul: rememorações para o futuro. Porto Alegre: Procuradoria-Geral de Justiça, 2001, p. 361.

15 MARTINS, Cyro; e SLAVUTZKY, Abrão. Para início de conversa. Porto Alegre: Movimento, 1990, p. 69.

16 A respeito da ANL no Rio Grande do Sul, cf. KONRAD, Diorge Alceno. 1935: a Aliança Nacional Libertadora no Rio Grande do Sul. Porto Alegre: PUCRS, 1994. Dissertação (Mestrado em História).
17 GRAWUNDER, Maria Zenilda. Instituição literária: uma análise da legitimação da obra de Dyonélio Machado. Porto Alegre: EDIPUCRS, 1997, p. 61.

18 A única ausência gritante foi a do intelectual-político Raul Pilla, militante do então proibido Partido Libertador. Notícias sobre a festa, com a lista dos intelectuais presentes, podem ser vistas em Jornal do Estado, Porto Alegre, 16 de novembro de 1940 , p. 7. Vali-me da cópia publicado como anexo, em KONRAD, Gláucia Vieira Ramos. A política cultural do Estado Novo no Rio Grande do Sul: imposições e resistências. Porto Alegre: PUCRS, 1994 (dissertação de mestrado em História).

19 MACHADO, Dyonélio. Memórias de um pobre homem. Porto Alegre: IEL, 1990, p. VII.

20 Revista do Globo, Porto Alegre, 29 de outubro de 1938 , p. 33.

21 KONRAD, op. cit., p. 196.

22 A respeito da situação na década de 1920, cf. GERTZ, René E. O aviador e o carroceiro: política, etnia e religião nos anos 1920. Porto Alegre: EDIPUCRS, 2002, p. 89-123. Sobre a atuação de D. João Becker durante todo esse período, veja ISAIA, Arthur César. Catolicismo e autoritarismo no Rio Grande do Sul. Porto Alegre: EDIPUCRS, 1998. No período do Estado Novo, uma das articulações importantes no campo intelectual foi a da criação da Faculdade de Filosofia da então Universidade de Porto Alegre, a qual pretendia representar uma cunha a ser introduzida na universidade para minar o caráter positivista agnóstico que a teria caracterizado desde sua fundação. Quanto a esse aspecto, cf. TRINDADE, Fernando Casses. Uma contribuição à história da Faculdade de Filosofia da UFRGS. Revista do Instituo de Filosofia e Ciências Humanas, Porto Alegre: UFRGS, ano 10, p. 1982.

23 BERTASO, José Otávio. A Globo da Rua da Praia. Rio de Janeiro: Globo, 1993, p. 171.

24 A situação, naturalmente, iria ficar pior, após a "intentona comunista", de novembro de 1935.

25 MARQUES, Alexandre Kohlrausch. A questão italo-abissínia: os significados atribuídos à invasão italiana à Etiópia, em 1935, pela intelectualidade gaúcha. Porto Alegre: UFRGS, 2008. Dissertação (Mestrado em História).

26 Em suas memórias, Veríssimo afirma que “o documento continha um protesto direto e veemente contra a invasão da Abissínia pelas tropas de Mussolini" (VERISSIMO, Érico. Solo de clarinete [v. I]. Porto Alegre: Globo, 1976, p. 256).

27 Muito provavelmente, a referência à situação no estado tenha como pano de fundo - além das medidas decorrentes do fechamento da ANL - 
o enfrentamento explícito, desde a inauguração da exposição alusiva ao centenário da Revolução Farroupilha, em setembro, entre Flores da Cunha e Getúlio Vargas. Os "idiotas de mal disfarçado fascismo", certamente, eram os integralistas.

28 Sobre Rivadávia de Souza, cf. GERTZ, O Estado Novo no Rio Grande do Sul, p. 128.

29 VERISSIMO, op. cit., p. 256.

30 Em 1994, a presença do nome de Érico Verissimo entre os signatários do manifesto "Pela causa da Itália" deu origem a um famoso affair intelecto-jornalístico, porque um articulista utilizou esse documento para criticar os posicionamentos políticos do escritor. Somente alguns anos depois, foi localizado o citado desmentido publicado pelos três intelectuais no jornal. Uma das versões sobre o episódio de 1994 pode ser visto em SILVA, Juremir Machado da. A miséria do jornalismo brasileiro: as (in)certezas da mídia. Petrópolis: Vozes, 2000, p. 106-115.

31 Que assinara o manifesto "Pala causa da Itália".

32 Ao mesmo tempo, Veríssimo, desde muito cedo, mostrou-se favorável ao alinhamento com os Estados Unidos (o "pan-americanismo"). Coerente com essa posição, foi um dos fundadores e primeiro presidente do Instituto Cultural Brasileiro Norte-Americano, em outubro de 1938 (KONRAD, Gláucia, op. cit., p. 132).

33 GERTZ, O Estado Novo no Rio Grande do Sul, p. 133-135.

34 Ele está relativamente bem estudado em TRINDADE, Fernando Casses. A polêmica entre Érico Verissimo e o Pe. Leonardo Fritzen, S. J. Revista do Instituto de Filosofia e Ciências Humanas, Porto Alegre: UFRGS, ano 11/12, p. 35-98, 1983/1984; e BATISTA, Karina Ribeiro. "Caso Fritzen": a polêmica em torno de $O$ resto é silêncio, de Érico Verissimo. Porto Alegre: PUCRS, 2004. Dissertação (Mestrado em Letras). O próprio Érico afirmou em suas memórias: "Eu queria que meu gesto [de processar o padre] fosse interpretado como um protesto contra a situação política vigente no país" (VERISSIMO, op. cit., p. 280).

35 Cf. GERTZ, O Sonderweg do Rio Grande do Sul.

\section{Bibliografia}

BATISTA, Karina Ribeiro. "Caso Fritzen": a polêmica em torno de $O$ resto é silêncio, de Érico Verissimo. Porto Alegre: PUCRS, 2004. Dissertação (Mestrado em Letras).
BELLINTANI, Adriana Iop. Conspiração contra o Estado Novo. Porto Alegre: EDIPUCRS, 2002.

BERTASO, José Otávio. A Globo da Rua da Praia. Rio de Janeiro: Globo, 1993.

BITTENCOURT, Dario de. "Curriculum vitae" - documentário - (1910-1957). Porto Alegre: Ética Impressora Ltda., 1958.

FÉLIX, Loiva Otero. Histórias de vida do Ministério Público do Rio Grande do Sul: rememorações para o futuro. Porto Alegre: Procuradoria-Geral de Justiça, 2001.

GERTZ, René E. Intelectuais gaúchos pensam o Rio Grande do Sul. Estudos Ibero-Americanos, Porto Alegre: PUCRS, v. X, n. 1, p. 79-113, 1984.

GERTZ, René E. O ciclo de Vargas segundo Veríssimo. In: GONÇALVES, Robson Pereira (Org.). O tempo e o vento: 50 anos. Bauru/Santa Maria: Edusc/EditoraUFSM, 2000, p. 199-205.

GERTZ, René E. O aviador e o carroceiro: política, etnia e religião nos anos 1920. Porto Alegre: EDIPUCRS, 2002.

GERTZ, René E. O Estado Novo no Rio Grande do Sul. Passo Fundo: Editora da UPF, 2005.

GERTZ, René E. O Sonderweg do Rio Grande do Sul. Estudos Ibero-Americanos, Porto Alegre: PUCRS, v. 37, n. 2, p. 215-321, 2011.

GRAWUNDER, Maria Zenilda. Instituição literária: uma análise da legitimação da obra de Dyonélio Machado. Porto Alegre: EDIPUCRS, 1997.

GUIMARÃES, Manoel Luis Salgado. Nação e civilização nos trópicos: o Instituto Histórico e Geográfico Brasileiro e o projeto de uma história nacional. Estudos históricos, Rio de Janeiro, FGV, n. 1, p. 5-27, 1988.

HENTSCHKE, Jens R. Positivism gaúcho-style: Júlio de Castilho's dictatorship and its impact on state and nation-building in Varga's Brazil. Berlim: Verlag für Wissenschaft und Forschung GmbH, 2004. 
ISAIA, Arthur César. Catolicismo e autoritarismo no Rio Grande do Sul. Porto Alegre: EDIPUCRS, 1998.

KONRAD, Diorge Alceno. 1935: a Aliança Nacional Libertadora no Rio Grande do Sul. Dissertação (Mestrado em História) - Pontifícia Universidade Católica do Rio Grande do Sul, Porto Alegre, PUCRS, 1994.

KONRAD, Gláucia Vieira Ramos. A política cultural do Estado Novo no Rio Grande do Sul: imposições e resistências. Dissertação (Mestrado em História) - Pontifícia Universidade Católica do Rio Grande do Sul, Porto Alegre, PUCRS, 1994.

MACHADO, Dyonélio. Memórias de um pobre homem. Porto Alegre: IEL, 1990.

MACIEL, Anor Butler. Nacionalismo - o problema judaico e o nacional-socialismo. Porto Alegre: Globo, 1937.

MACIEL, Anor Butler. Subsídios para o estudo da estrutura política do Estado Novo. Porto Alegre: Globo, 1937.

MARQUES, Alexandre Kohlrausch. A questão italo-abissínia: os significados atribuídos à invasão italiana à Etiópia, em 1935, pela intelectualidade gaúcha. Dissertação (Mestrado em História) - Pontifícia Universidade Católica do Rio Grande do Sul, Porto Alegre, PUCRS, 2008.

MARTINS, Cyro; SLAVUTZKY, Abrão. Para início de conversa. Porto Alegre: Movimento, 1990.

MICELI, Sérgio. Intelectuais e classe dirigente no Brasil (1920-1945). São Paulo: Difel, 1979.

PÉCAUT, Daniel. Os intelectuais e a política no Brasil: entre o povo e a nação. São Paulo: Ática, 1990.

ROLLAND, Denis. O estatuto da cultura no Estado Novo: entre o controle das culturas nacionais e a instrumentalização das culturas estrangeiras. In: BASTOS, Elide Rugai; RIDENTI, Marcelo; ROLLAND, Denis (Org.). Intelectuais: sociedade e política. São Paulo: Cortez, 2003, p. 85-111.

SANTOS, José Antônio dos. Prisioneiros da História: trajetórias de intelectuais na imprensa negra meridional. Tese (Doutorado em História) - Pontifícia Universidade Católica do Rio Grande do Sul, Porto Alegre, PUCRS, 2011.

SILVA, Juremir Machado da. A miséria do jornalismo brasileiro: as (in)certezas da mídia. Petrópolis: Vozes, 2000.

SILVEIRA, Éder. Tupi or not tupi: nação e nacionalidade em José de Alencar e Oswald de Andrade. Porto Alegre: EDIPUCRS, 2009.

TRINDADE, Fernando Casses. Uma contribuição à história da Faculdade de Filosofia da UFRGS. Revista do Instituo de Filosofia e Ciências Humanas, Porto Alegre: UFRGS, ano 10, 1982.

TRINDADE, Fernando Casses. A polêmica entre Érico Verissimo e o Pe. Leonardo Fritzen, S. J. Revista do Instituto de Filosofia e Ciências Humanas, Porto Alegre: UFRGS, ano 11/12, p. 35-98, 1983/1984.

VELLOSO, Mônica Pimenta. Os intelectuais e a política cultural do Estado Novo. Rio de Janeiro: FGV/CPDOC, 1987.

VERÍSSIMO, Érico. Solo de clarinete, v. I, Porto Alegre: Globo, 1976.

VIEIRA, Newton Colombo de Deus. Além de Gustavo Barroso: o antissemitismo na Ação Integralista Brasileira (1932-1937). Porto Alegre: PUCRS. Dissertação (Mestrado em História) Pontifícia Universidade Católica do Rio Grande do Sul, Porto Alegre, PUCRS, 2012. 